\title{
CORRECTION
}

View Article Online

View Journal I View Issue

Check for updates

Cite this: Soft Matter, 2020,

16,276

\section{Correction: Comparison of bulk and microfluidic methods to monitor the phase behaviour of nanoparticles during digestion of lipid-based drug formulations using in situ X-ray scattering}

\author{
Linda Hong, (D) ab Muhsincan Sesen, (D) ${ }^{c}$ Adrian Hawley, ${ }^{d}$ Adrian Neild, (D) ${ }^{c}$ \\ Patrick T. Spicer (D) and Ben J. Boyd (D) *ab
}

\begin{abstract}
DOI: 10.1039/c9sm90251a rsc.li/soft-matter-journal
\end{abstract}

Correction for 'Comparison of bulk and microfluidic methods to monitor the phase behaviour of nanoparticles during digestion of lipid-based drug formulations using in situ X-ray scattering' by

The authors regret that in the original paper, incorrect details were given for ref. 12, 17 and 30. The correct versions of these citations are given below as ref. 1, 2 and 3, respectively.

The Royal Society of Chemistry apologises for these errors and any consequent inconvenience to authors and readers.

\section{References}

1 A. Ghazal, M. Gontsarik, J. P. Kutter, J. P. Lafleur, A. Labrador, K. Mortensen and A. Yaghmur, J. Appl. Crystallogr., 2016, 49, 2005-2014.

2 J. Khan, T. Rades and B. J. Boyd, Pharm. Res., 2016, 33, 548-562.

3 A. J. Clulow, M. Salim, A. Hawley and B. J. Boyd, Chem. Phys. Lipids, 2017, 211, 107-116.

\footnotetext{
${ }^{a}$ Drug Delivery, Disposition and Dynamics, Monash Institute of Pharmaceutical Sciences, Monash University (Parkville Campus), 381 Royal Parade, Parkville, VIC 3052, Australia.E-mail:Ben.Boyd@monash.edu

${ }^{b}$ ARC Centre of Excellence in Convergent Bio-Nano Science and Technology, Monash Institute of Pharmaceutical Sciences, Monash University (Parkville Campus), 381 Royal Parade, Parkville, VIC 3052, Australia

${ }^{c}$ Department of Mechanical and Aerospace Engineering, Monash University, Clayton, VIC 3800, Australia

${ }^{d}$ SAXS/WAXS Beamline, Australian Synchrotron, 800 Blackburn Rd, Clayton, VIC 3150, Australia

${ }^{e}$ School of Chemical Engineering, University of New South Wales, Sydney, NSW 2052, Australia
} 